\title{
Beyond Double-Stranded RNA-Type I IFN Induction by 3pRNA and 0ther Viral Nucleic Acids
}

\author{
M. Schlee ${ }^{1} \cdot$ W. Barchet ${ }^{1} \cdot$ V. Hornung ${ }^{2}$ G. Hartmann ${ }^{1}(-)$ \\ ${ }^{1}$ Abteilung für Klinische Pharmakologie, Universitätsklinikum Bonn, \\ Siegmund-Freud-Straße 25. 53127 Bonn, Germany \\ gunther.hartmann@ukb.uni-bonn.de \\ ${ }^{2}$ Division of Clinical Pharmacology, Department of Internal Medicine, University \\ of Munich, 80336 Munich, Germany
}

1 History of Type I IFN Induction

2 Long Double-Stranded RNA and the Activation

of Antiviral Effector Molecules

3 Type I IFN Induction by Nucleic Acids in Immune Cells

RNA Modifications Contribute to the Distinction

of Self- Versus Non-self RNA in Immune Cells

6

Detection of RNA in the Cytosol: 3pRNA Is

the Ligand for RIG-I

$7 \quad$ Virus Specificity of 3pRNA Recognition

8

MDA-5 Recognizes Poly IC

9

Cell-Type-Dependent Sensing of Viral RNA

10

Conclusion and Future Directions.

References

Abstract Production of type I IFN is the key response to viral infection. Since the discovery of type I IFNs in 1957, long double-stranded RNA formed during replication of many viruses was thought to be responsible for type I IFN induction, and for decades double-stranded RNA-activated protein kinase (PKR) was thought to be the receptor. Recently, this picture has dramatically changed. It now became evident that not PKR but two members of the Toll-like receptor (TLR) family, TLR7 and TLR9, and two cytosolic helicases, RIG-I and MDA-5, are responsible for the majority of type I IFNs induced upon recognition of viral nucleic acids. In this review, we focus on the 
molecular mechanisms by which those innate immune receptors detect viral infection. Based on the recent progress in the field, we now know that TLR7, TLR9, and RIG-I do not require long double-stranded RNA for type I IFN induction.

1

\section{History of Type I IFN Induction}

Type I IFNs (IFN- $\alpha$ isoforms and IFN- $\beta$ ) are regarded as the dominant mediators of antiviral defense in vertebrates. Since their initial discovery half a century ago as acid-stable, soluble factors "interfering" with viral proliferation in cultured cells (Isaacs and Lindenmann 1957; Nagano and Kojima 1958), intense research has focused on type I IFN receptor signaling and the plethora of type I IFN-mediated effects (Theofilopoulos et al. 2005). For the host, an intact type I IFN response is critical for the survival of many viral infections (Gresser et al. 1976; Muller et al. 1994). Sensing of viral replication has been proposed to be responsible for triggering the production of type I IFNs by infected host cells. However, the specific host immune receptors and their respective molecular ligands remained elusive until very recently. Moreover, to mount an appropriate antiviral response, the innate immune system must distinguish viruses from bacteria, fungi, and multicellular parasites. Charles Janeway was the first to propose that the detection of highly conserved pathogen-associated molecular patterns (PAMPs) may be mastered by a limited number of germline-encoded pattern recognition receptors (PRRs) (Janeway 1989). A few years later, the first experimental evidence of such a receptor came from the fruit fly (Lemaitre et al. 1996). Shortly afterwards, a member of the family of toll-like receptors (TLR), the mammalian homolog of Drosophila toll, was demonstrated to be responsible for detecting lipopolysaccharides (LPS), a characteristic component of the cell walls of Gram-negative bacteria (Medzhitov et al. 1997; Poltorak et al. 1998). This observation was confirmed by the subsequent generation of TLR4-deficient mice (Hoshino et al. 1999).

Parasites, bacteria, and fungi rely on a multitude of molecules that are distant in evolutionary terms from the mammalian organism, and are thus readily discernible as non-self by members of the Toll-like receptor (TLR) and NODlike receptor (NLR) families (reviewed in Meylan et al. 2005). In sharp contrast, all components of viruses are produced within the infected host cell, and therefore lack distinguishable non-self molecular patterns. Nevertheless, viruses are promptly recognized by the innate immune system and elicit pronounced antiviral type I interferon and cytokine responses. Shortly after the discovery of type I interferons, it was proposed that viral nucleic acids could be stimulating the type I IFN response (Isaacs et al. 1963). Many viruses synthesize 
double-stranded RNA (dsRNA) during their replication cycle (Baltimore et al. 1964; Montagnier and Sanders 1963), whereas dsRNA was thought to be absent in uninfected cells. Therefore dsRNA formed during viral infection was postulated to be the molecular signature of viral infection. In support of this hypothesis, the enzymatically generated double-stranded RNA polynucleotide polyinosinic:polycytidylic acid (poly I:C) was found to be a potent inducer of type I IFN (Field et al. 1967). Although the authors carefully emphasized that all other double-stranded polynucleotides were inactive, the notion that long viral double-stranded RNA elicits type I IFN became commonplace, and poly $\mathrm{I}$ :C has been used as an interferon-inducing mimic of viral dsRNA ever since.

\section{2 \\ Long Double-Stranded RNA and the Activation of Antiviral Effector Molecules}

In early attempts to uncover the inducers of interferon and of other mediators of antiviral activity, IFN- $\alpha$ and poly I:C-treated or reticulocyte extracts were analyzed. Chromatographic separation of lysates revealed proteins that were increased by preincubation with IFN- $\alpha$, and whose enzymatic activity depended on the presence of dsRNA (usually poly I:C) (Farrell et al. 1978; Hovanessian et al. 1977; Zilberstein et al. 1978). Two proteins, interferon inducible double-stranded RNA-activated protein kinase (PKR) and the $2^{\prime}, 5^{\prime}$ oligoadenylate synthetase (OAS) could be affinity purified using poly I:C-cellulose (Farrell et al. 1978; Hovanessian et al. 1977). Both activated PKR and OAS were found to block translation of viral RNA by distinct mechanisms. In the presence of poly I:C, OAS catalyzes the synthesis of $2^{\prime}, 5^{\prime}$ oligomers of adenosine (2-5As) (Hovanessian et al. 1977; Zilberstein et al. 1978), which activate RNase L (Farrell et al. 1978). RNase L in turn degrades single-stranded viral and cellular RNAs (Farrell et al. 1978) in a sequence-independent manner (Minks et al. 1979). Consequently RNase L-deficient mice displayed a reduced antiviral activity of IFN- $\alpha$, as well as impaired apoptosis (Zhou et al. 1997). In contrast, the serine threonine kinase PKR was found to more specifically block the translation of viral RNA (Farrell et al. 1978) by phosphorylation of the eukaryotic translation initiation factor eIF2a.

Besides its function in limiting translation of viral protein, PKR was also reported to activate NF- $\kappa B$ (Kumar et al. 1994). PKR was therefore proposed as a key receptor mediating virus- and dsRNA-induced production of type I interferons (Kumar et al. 1994). However, these findings remained controversial, as other studies that examined PKR-deficient mice and cells (Chu et al. 1999; 
Iordanov et al. 2001; Maggi et al. 2000; Smith et al. 2001; Yang et al. 1995) found no defects in the induction of interferon in response to poly I:C or viral infection that could not be overcome with type I IFN pretreatment.

Further analysis revealed that PKR is not only activated by poly I:C but is able to interact with dsRNA as short as $11 \mathrm{bp}$. However, at least $30 \mathrm{bp}$ are required to activate PKR kinase activity (Manche et al. 1992). In another study (Zheng and Bevilacqua 2004), recombinant PKR could also be activated by RNA oligonucleotides containing a 16-bp dsRNA stem loop in combination with a more than 11bp-long single-stranded RNA part at the $5^{\prime}$ or $3^{\prime}$ end. All these studies question the often quoted requirement of a dsRNA molecule longer than $30 \mathrm{bp}$; furthermore, it became evident that the translational shut-down by PKR is not linked to the induction of type I IFN synthesis and secretion. The finding that $\mathrm{PKR}^{-1-}$ cells still produce type I IFNs spurred further research on receptors capable of recognizing long double-stranded RNA. Such investigations led to a member of the Toll-like receptor (TLR) family, TLR3, which was proposed to bind to long dsRNA and to induce IFN- $\beta$ (Alexopoulou et al. 2001). TLRs are transmembrane receptors that were shown to recognize a variety of conserved pathogenassociated molecular patterns (PAMPs) of bacterial, fungal, and parasitic origin. The study of Alexopoulou et al. was the first to demonstrate a role for TLRs in the recognition of viruses. TLR9 was found to be the receptor for unmethylated CpG motifs in DNA (Hemmi et al 2000); however, CpG-DNA at first was thought to be characteristic for bacterial DNA, and the role of TLR9 in detecting DNA viruses was only proposed later (Krug et al. 2004a, 2004b; Tabeta et al. 2004). Upon engagement with their specific ligands, TLRs trigger signaling pathways that lead to the activation of NF- $\mathrm{\kappa B}$ and IRFs (signaling of TLRs reviewed in Moynagh 2005). TLR3 was found to induce type I IFNs upon poly I:C stimulation by activation of the kinase TBK1, which phosphorylates the transcription factor IRF3, resulting in the induction of IFN- $\beta$ (Doyle et al. 2002; Fitzgerald et al. 2003; Sharma et al.2003). Another group reported that TLR3 is activated by ssRNA (Kariko et al. 2004b); however, TLR3-deficient mice and mice deficient in the signaling adapter TRIF (Gitlin et al. 2006; Kato et al. 2006) still responded to poly I:C. Moreover, dendritic cells derived from TLR3-deficient mice were still stimulated by dsRNA transfected into the cytosol (Diebold et al. 2003).

3

\section{Type I IFN Induction by Nucleic Acids in Immune Cells}

Unlike tumor cell lines, which were examined in early studies on type I IFN and dsRNA, primary immune cells such as peripheral blood mononuclear cells (PBMCs) express a wide spectrum of functional TLRs. Different immune cell 
subsets express distinct patterns of TLRs (Hornung et al. 2002). Plasmacytoid dendritic cells (PDCs) (reviewed in Colonna et al. 2004) are the major producers of early type I IFN production upon viral infection. PDCs express TLR7 and TLR9 but not TLR3. Both TLR7 and TLR9 are located in the endosomal compartment and signal via the adaptor molecules MyD88, IRAK1, and TRAF6, leading to activation of IRF7 and the induction of type I interferons as reviewed by Moynagh (2005). In addition, recent studies show that TRAF3 plays a crucial role in the MyD88-dependent signaling cascade (Hacker et al. 2005; Oganesyan et al. 2005). Single-stranded DNA and the small antiviral compound R848 had been shown to induce IFN in PDCs dependent on TLR9 and TLR7, respectively (Hemmi et al. 2000, 2002; Jurk et al. 2002; Krug et al. 2001b; Rothenfusser et al. 2002). TLR9 detects unmethylated so-called CpG motifs in single-stranded DNA (Hemmi et al. 2000). Different classes of synthetic CpG oligodeoxynucleotides (ODN) were developed based on the distinct effects on the two TLR9-expressing immune cell types: PDCs and B cells (Hartmann et al. 2003; Hartmann and Krieg 2000; Krug et al. 2001a).

In contrast to TLR3, both TLR7 and 9 depend on the signaling adapter MyD88. Accordingly, PDCs derived from TLR9- or MyD88-deficient mice are unable to produce type I IFN in response to DNA viruses such as herpes simplex viruses (HSV) and murine cytomegalovirus (MCMV) (Krug et al. 2004a, 2004b; Lund et al. 2003; Tabeta et al. 2004). While TLR9 was responsible for detecting viral DNA, TLR7 was shown to recognize RNA: TLR7 detects synthetic short (20-27 bases) single-stranded RNA (Diebold et al. 2004; Heil et al. 2004) and short interfering double-stranded RNA (siRNA) (Hornung et al. 2005; Judge et al. 2005; Sioud 2005; reviewed in Schlee et al. 2006). The amount of type I interferon induction was dependent on the RNA sequence. Ironically, Hornung and colleagues came across a very potent type I interferon inducing small RNA sequence core motif (5'-GUCCUUCAA-3') in the attempt to knock down the interferon inducer TLR9 in PDCs using the siRNA technology (Hornung et al. 2005). It was demonstrated that these siRNAs induce systemic immune activation in mice, and that the immunological activity required TLR7. Of note, the same siRNA did not induce type I interferon in immortalized human embryonic kidney cells (HEK293), which produced type I interferon in response to poly I:C. In subsequent studies, similar findings were reported by Judge et al. (2005) (identifying a core motif 5'-UGUGU-3') and Sioud (2005). In all three studies, transfection with cationic lipids (e.g., DOTAP, lipofectamine) or cationic polymers (e.g., PEI, polyethylenimine) was essential for the immunological activity of siRNA. The same applies for the immunological activity of single-stranded RNA (Diebold et al. 2004; Heil et al. 2004; Scheel et al. 2005). 


\section{4 \\ RNA Modifications Contribute to the Distinction of Self- Versus Non-self RNA in Immune Cells}

While for short RNA oligonucleotides the immunological activity is clearly sequence dependent (Hornung et al. 2005; Judge et al. 2005), for long RNA molecules such as mRNA, sequence specificity of immunological activity is less prominent (Scheel et al. 2005). This raises the question of how the immune system is able to distinguish between self and non-self (for example viral) RNA. This question was addressed recently by Kariko and colleagues (2005) who showed that human mitochondrial RNA, when transfected into monocyte-derived dendritic cells, provoked secretion of TNF- $\alpha$ at similar quantities compared to total RNA isolated from Escherichia coli. In contrast, RNA of other cellular compartments showed no immunological activity. The authors proposed that mammalian RNA is masked by naturally occurring nucleoside modifications that are expected to be similar in closely related species. According to this concept, mitochondrial RNA is stimulatory since it resembles bacterial rather than mammalian RNA. In healthy cells, mitochondrial RNA will not be released. In contrast to other self-RNA, mitochondrial RNA never enters the cytosolic compartment. As a consequence, mitochondrial RNA under healthy conditions is not detected by cytosolic mechanisms of detection. Only if the cell is lysed can mitochondrial RNA enter the endosomal compartment of immune cells via phagocytosis. Indeed, the stimulatory effect of in vitro RNA transcripts composed of unmodified nucleotides in their study could be abrogated by incorporation of modified nucleosides such as pseudouridine, 5-methylcytidine, N6-methyladenosine, inosine, and N7methylguanosine. In order to examine modification sensitivity of different TLRs, HEK293 cells expressing TLR3, TLR7, TLR8, or TLR9 were transfected with RNA containing modified nucleosides. Transfection of unmodified RNAs stimulated IL-8 production (sensitive readout for immunoactivation of HEK293 cells) in HEK293 cells overexpressing TLR3, 7, and 8. Interestingly, RNA recognition by TLR3, TLR7, and TLR8 is suppressed by the presence of different types of modified nucleotides within the RNA ligand. TLR3 was the least sensitive receptor with regard to suppression by nucleoside modifications. Furthermore, the authors showed that in monocyte-derived dendritic cells, $5 \%-10 \%$ of modified nucleosides were sufficient to inhibit TNF- $\alpha$ secretion by $75 \%-90 \%$. Together, these results show that RNA modification contributes to the distinction of self versus non-self RNA by the immune system. 
5

Type I IFN Induction by RNA Mediating RNA Interference

Further insight into the properties that render RNA molecules stimulatory to the immune system is driven by siRNA technology. Based on studies by Tuschl and colleagues (Elbashir et al. 2001), siRNA is now used worldwide as a robust tool for target-specific gene silencing in cell lines and human primary cells. However, depending on the mode of synthesis and the sequences used to generate siRNA, also nonspecific, so-called nonspecific off-target effects of siRNAs were observed.

To overcome limitations with the transfection of synthetic siRNA, vectorbased (e.g., lentiviral) expression systems for the introduction of short hairpin siRNAs (shRNA) mimicking siRNAs were developed (Brummelkamp et al. 2002; Harborth et al. 2003; Paddison et al. 2002). The most commonly used shRNA expression system consists of a RNA-polymerase III dependent promoter driving the expression of two complementary 19- to 29-bp RNA sequences linked by a short loop of 4-10 nt. The resulting transcript is exported to the cytoplasm and processed by dicer. Lentiviral vectors haboring the Pol III-shRNA expression cassette (Li et al. 2003; Rubinson et al. 2003; Tiscornia et al. 2003) allow RNAi-mediated gene silencing via siRNA in cells that are otherwise difficult to transfect.

Sequence specificity of gene silencing by such shRNA was questioned by Bridge et al. (Bridge et al. 2003), who demonstrated that infection of human lung fibroblasts with Pol III-shRNA containing lentivirus directed against the gene MORF4L1 not only silenced MORF4L1 but also stimulated interferoninducible genes such as $2^{\prime}, 5^{\prime}$-OAS, an indicator of type I interferon. The IFNinducing effect was dependent on the sequence and the dose of the vector; seven of 23 shRNAs targeting different genes exhibited IFN induction. In contrast, transfection of synthetic siRNA with the same putative IFN-inducing sequences led to sequence-specific silencing without triggering an IFN response. Northern blot analysis of shRNA showed that the majority of shRNA transcripts were correctly processed to $20 \mathrm{nt}$ transcripts. The authors speculated that remaining unprocessed transcripts could be detected by cytosolic RNA sensing receptors. In the follow-up paper, the group of Iggo (Pebernard and Iggo 2004), further correlated the U6 promoter sequence with OAS induction. This study revealed that the region between -2 (the end of the promoter) and +2 (the start of RNA transcript) is crucial for the immune stimulatory effect, which was lost when they used the endogenous human sequence (CCGA). Further mutations leading to a partial mismatch in the shRNA (predicted to create a 14-bp duplex) suggested that stimulation required more than a 14-bp duplex. 
William's group (Sledz et al. 2003) described the induction of IFN target genes by transfection of synthetic siRNAs into a human glioblastoma cell line (T98G) or a renal carcinoma cell line (RCC). When comparing the two studies from Bridge and colleagues and from Sledz and colleagues, it is important to note that different cell lines (Bridge, human lung fibroblasts; Sledz, RCC and T98G) and different ways of siRNA generation (Bridge, synthetic siRNAs and shRNAs; Sledz, synthetic siRNA and T7-phage-polymerase siRNA) were used.

Using mouse embryonic fibroblasts (MEFs) with different gene deficiencies related to the IFN response system, Sledz et al. proposed that PKR was the interferon-inducing receptor for siRNAs. Later, the same group postulated a different siRNA receptor (RIG-I, see below) in T98G cells (Marques et al. 2006). Of note, in the two studies published by Bridge et al. (2003) and Sledz et al. (2003), type I interferon was not analyzed at the protein level.

Kariko et al. (2004a) suggested that TLR3 was responsible for the induction of type I IFN by siRNA. These data are based on keratinocyte (HaCaT) and HEK 293 cells, which responded to synthetic siRNA but not to the singlestranded components (ssRNA) by secretion of low amounts of IFN- $\beta$ that was comparable to stimulation with poly I:C. Overexpression of TLR3 in HEK 293 cells resulted in fourfold higher induction of type I IFN secretion in response to transfected siRNA. However, overexpression of NF-KB-inducing receptors such as TLR3 may also contribute indirectly to the enhanced type I IFN response induced by siRNA, for example by upregulating IFN-inducible cytosolic RNA receptors. For example, TLR3 overexpressing HEK 293 cells secrete more IL-8 than empty vector or TLR9 overexpressing HEK 293 cells (Kariko et al. 2005); consequently, such studies do not necessarily provide evidence for a direct interaction between siRNA and TLR3.

Kim et al. (2004) showed that the induction of type I IFN by siRNA depended on the use of T7-RNA polymerase (T7 RNAP) for siRNA generation. In contrast to Bridge et al. (2003) and Sledz et al. (2003), in the study by Kim and colleagues, type I IFN was measured at the protein level, which is less sensitive than measuring IFN-dependent responses on the transcriptional level and thus underscores the magnitude of the IFN response they reported. In their study, Kim and colleagues examined siRNAs targeting the early ICP4 gene of HSV-1. Only T7 RNAP-derived transcripts but not synthetic siRNA elicited a potent antiviral activity when transfected into HEK 293 cells. The same antiviral activity was observed by transfection of T7 transcripts with unrelated sequences. Analysis of supernatants revealed the presence of substantial amounts of IFN- $\alpha$ and IFN- $\beta$ protein. These results were reproduced in HeLa cells, as well as K562, CEM, and Jurkat cells. It is well known that unlike capped mammalian mRNA, the $5^{\prime}$ ends of T7 transcripts harbor a triphosphate GTP-nucleotide. Treatment 
of T7 transcripts with RNase T1 (with the 5' end p-GGG removed, which was single-stranded in their case) and alkaline phosphatase was sufficient to completely abrogate interferon-inducing activity. Additional experiments using T3 and Sp6 phage RNA polymerases demonstrated similar induction of type I IFN. The examination of multiple cell lines by Kim et al. (2004) pointed to a powerful ubiquitously expressed sensor for short triphosphate RNA.

\section{6 \\ Detection of RNA in the Cytosol: 3pRNA Is the Ligand for RIG-I}

Yoneyama and colleagues identified the interferon-inducing cytoplasmic DexD/ $\mathrm{H}$ box RNA helicase RIG-I, containing a caspase recruitment domain (CARD) (Yoneyama et al. 2004). Expression of the CARD domain sensitized cells to activate the transcription factor IRF3, leading to the induction of the IFN- $\beta$ promoter. Later on it was shown that this pathway involves the IRF3 kinase TBK1, which is activated by the newly characterized adaptor protein IPS-1, also known as Cardif, MAVS, or VISA (Kawai et al. 2005; Meylan et al. 2005; Seth et al. 2005; Xu et al. 2005; reviewed in Sen and Sarkar 2005). In overexpression experiments, RIG-I was shown to bind poly I:C. However, overexpression of a dominant negative mutant of RIG-I impaired IRF3 activation by Newcastle disease virus (NDV), a negative-strand RNA virus, while IRF3 activation by poly I:C was not inhibited. Subsequent studies with $\mathrm{RIG}^{-\mathrm{I}^{--}}$mice and MEFs (Kato et al. 2006) showed no defect in the response to poly I:C.

Hornung and colleagues (2006) demonstrated that RIG-I detects in vitro transcribed RNA. RNA with a triphosphate at the $5^{\prime}$ end (now termed 3pRNA), which is generated during in vitro transcription, was identified to be the ligand for RIG-I. The minimal length of 3pRNA was 19 nucleotides. The activity of 3pRNA was independent of double-strand formation. Both exogenous 3pRNA transfected into the cell and endogenously formed 3pRNA (expression of T7 RNA polymerase) activated RIG-I. Genomic RNA prepared from a negative-strand RNA virus and RNA prepared from virus-infected cells, but not RNA from noninfected cells, triggered a potent IFN- $\alpha$ response in a $5^{\prime}$-triphosphate-dependent manner. Binding studies of RIG-I and 3pRNA revealed a direct molecular interaction. The $5^{\prime}$ capping or incorporation of modified nucleotides such as pseudouridine, 2-thiouridine, and 2'-O-methylated uridine in place of uridine in short 3pRNA strongly diminished IFN- $\alpha$ induction. In a parallel study, Pichlmair et al. (2006) attributed the inhibitory effect of the influenza virus protein NS1 to its binding and inhibition of the RIG-I triphosphate RNA complex. 


\section{7 \\ Virus Specificity of 3pRNA Recognition}

These results provide evidence that uncapped unmodified 3pRNA is detected by RIG-I in the cytosol of eukaryotic cells. Of note, all primer-independent RNA transcripts in a normal uninfected cell initially contain a $5^{\prime}$-triphosphate end. However, most if not all self-RNA species entering the cytosol lack a free $5^{\prime}$ triphosphate end. Before self-RNA leaves the nucleus, RNA is further processed, which applies to RNA transcripts of all three DNA-dependent RNA polymerases (pol) in eukaryotes. Pol I transcribes a large polycistronic precursor of ribosomal RNA (rRNA) that contains the sequences for the mature rRNAs $(18,5.8 \mathrm{~S}$, 25-28S rRNA), two external transcribed spacers, and two internal transcribed spacers. This primary transcript is subjected to endo- and exonucleolytic processing steps to produce the mature rRNAs. The net result of this maturation process is a monophosphate group at the $5^{\prime}$ end of all pol I transcribed rRNAs (Fromont-Racine et al. 2003). Messenger RNAs (mRNAs) and small nuclear RNAs (snRNAs), which are transcribed by pol II, receive a 7-methyl guanosine group that is attached to the $5^{\prime}$-triphosphate of the nascent RNA by a process called capping (Shatkin and Manley 2000). Thus, upon export into the cytoplasm, no free triphosphate groups are found in pol II transcripts. All mature tRNAs (pol III) have a $5^{\prime}$-monophosphate (Xiao et al. 2002), as it is likely to apply to 5 S rRNA. U6 RNA receives a $\gamma$-monomethylphosphate cap structure following transcription. However, 7SL RNA (pol III) has a triphosphate at the $5^{\prime}$ end, and is present at high copy numbers in the cytosol. Therefore, the presence or absence of a $5^{\prime}$ triphosphate might not be the only structural feature of RNA responsible for the distinction of self and viral RNA.

It is well known that eukaryotic RNA undergoes significant modifications to its nucleosides and its ribose backbone. Among all nucleoside modifications, pseudouridinylation is one of the most common post-transcriptional modifications of RNA that appears to be universal among rRNAs and small stable RNAs such as splicing small nuclear RNAs (snRNAs), tRNAs, and small nucleolar RNAs (snoRNAs). However, the frequency and location of pseudouridinylated nucleotides vary phylogenetically. Intriguingly, eukaryotes contain far more nucleoside modifications within their RNA species. Human ribosomal RNA, for example, the major constituent of cellular RNA, contains ten times more pseudouridine and 25 times more 2-O-methylated nucleosides than E. coli rRNA (Rozenski et al. 1999). The same applies to eukaryotic tRNAs, the most heavily modified subgroup of RNA with up to $25 \%$ of modified nucleosides. The host machinery that guides nucleoside modifications and 2'-O-methylation of the ribose backbone is located in the nucleolus, and consists of RNA-protein 
complexes containing snoRNAs and several associated proteins (snoRNPs) (Decatur and Fournier 2003). Information on nucleolus-specific nucleoside modifications or ribose 2'-O-methylation of viral RNA genomes is limited. Since most RNA viruses do not replicate in the nucleus and modification is tightly confined to the sequence and structure of their target, extensive modification of viral RNA seems unlikely. Altogether, post-transcriptional modifications of eukaryotic RNA such as $5^{\prime}$ processing or capping, as well as nucleoside modifications or ribose backbone methylation, provide the molecular basis for the distinction of self-RNA generated in the nucleus from viral RNA of cytosolic origin containing $5^{\prime}$-triphosphate (3pRNA).

The mRNAs of viruses infecting eukaryotic cells also commonly contain 7-methyl guanosine cap-structures at their $5^{\prime}$ ends and poly(A) tails at their $3^{\prime}$ ends (Furuichi and Shatkin 2000). Some viruses make use of the host transcription machinery to acquire caps and poly(A) tails. RNA viruses that do not rely on the host transcriptional machinery produce their own capping enzymes or utilize other mechanisms such as snatching the $5^{\prime}$ terminal regions of host mRNAs. Despite these adaptations of viruses to the host transcriptional system, viral RNA synthesis leads to transient cytosolic RNA intermediates with an uncapped 5 '-triphosphate end. With notable exceptions such as the Picornavirus family (see below), viral RNA-dependent RNA polymerases (RdRp) initiate polymerase activity de novo, without a specific primer (Kao et al. 2001). As a consequence, these RdRp-dependent transcripts start with an uncapped $5^{\prime}$-triphosphate. This has been studied in great detail for the replication of positive-strand RNA viruses of the family of Flaviviridae (including the genera Flavivirus, Pestivirus, and Hepacivirus); members of all of these virus genera were reported as being recognized via RIG-I (Honda et al. 1998; Kato et al. 2006; Sumpter et al. 2005). Segmented NSV rely on a cap-snatched primer for mRNA transcription, yet initiate genomic and the complementary antigenomic RNA replication by a primer-independent de novo mechanism resulting in a $5^{\prime}$-triphosphateinitiated transcript (Honda et al. 1998; Neumann et al. 2004). NSV with a nonsegmented genome (order Mononegavirales), including the Paramyxoviruses and Rhabdoviruses, initiate both replication and transcription de novo leading to $5^{\prime}$-triphosphate RNA in the cytosol. Both the full-length replication products, vRNA and cRNA, and a short leader RNA, which is abundantly synthesized during initiation of transcription, maintain their $5^{\prime}$ triphosphate (Colonno and Banerjee 1978; Whelan et al. 2004), while the virus-encoded mRNA transcripts are further modified at their $5^{\prime}$ ends by capping and cap methylation. Consequently, genomic RNA from NSVs per se is expected to trigger an IFN-response without the need for replication and presumed dsRNA formation. 
Consistent with this notion, not only live virus but also RNA purified from NSV virions (VSV) has been shown to trigger strong type I interferon responses depending on RIG-I (Kato et al. 2006). Hornung and colleagues confirmed and extended these observations by demonstrating that dephosphorylation of the viral RNA isolates completely abolished the IFN-response, thereby indicating that the $5^{\prime}$-triphosphate moiety is strictly required for recognition (Hornung et al. 2006).

A notable exception are the viruses in the Picornavirus-like supergroup (picornavirus, potyvirus, comovirus, calicivirus, and other viruses), which exclusively employs a protein known as viral genome-linked protein (VPg) as a primer for both positive- and negative-strand RNA production. This protein primer is part of the precursor RdRp and is cleaved off as elongation of the initial complex occurs, usually to become a $5^{\prime}$-genome-linked protein (Lee et al. 1977). Thus during the life-cycle of Picornaviruses uncapped, triphosphorylated 5' ends are absent. Consequently, based on our studies, RIG-I is expected to be involved in the detection of Flaviviridae and NSV but not Picornaviruses. This is confirmed in a recent study (Kato et al. 2006).

A number of studies suggested that the helicases MDA-5 and RIG-I recognize dsRNA (Andrejeva et al. 2004; Rothenfusser et al. 2005; Yoneyama et al. 2004). The results in the work of Hornung and colleagues (2006) demonstrated that double-strand formation of RNA is not required for RIG-I-RNA interaction, and that dsRNA is not sufficient for RIG-I activation. These results further demonstrate that MDA-5 is not involved in 5'-triphosphate RNA recognition. Although there is convincing evidence that MDA- 5 is activated by the long dsRNA mimic poly I:C, activation of MDA-5 by natural long dsRNA is still controversial (Kato et al. 2006). Taken together, TLR3 is so far the only receptor that induces type I IFN upon binding of the natural molecule long dsRNA, but the contribution of TLR3 to type I IFN induction and viral clearance in vivo seems to be weak (Rudd et al. 2006).

There is good evidence that short dsRNA such as siRNA generated by Dicermediated cleavage of long dsRNA does not elicit a type I IFN response in nonimmune cells (Elbashir et al. 2001; Hornung et al. 2005; Kim et al. 2004). A recent study suggests that the two-nucleotide overhang at the $3^{\prime}$ end of dicer cleavage products are essential for the lack of immunorecognition of short dsRNA (Marques et al. 2006). The same study proposed that synthetic blunt-end short dsRNA is recognized via RIG-I. The conclusion that RIG-I is the receptor for blunt end short dsRNA is based on experiments using RIG-I overexpression and using anti-RIG-I siRNA (short dsRNA with two-nucleotide 3'overhangs) on top of stimulation with blunt end short dsRNA stimulation. RIG-I-deficient cells have not been examined in this study. This experimental design does not 
provide clear-cut evidence for the primary involvement of RIG-I in type I IFN induction by blunt-end short dsRNA. Furthermore, in the study by Hornung and colleagues, $5^{\prime}$ triphosphate blunt-end RNA and $5^{\prime}$ triphosphate 2-nt overhang RNA showed identical RIG-I ligand activity, suggesting that the molecular feature 2-nt overhang does not inhibit RIG-I-mediated recognition (Hornung et al. 2006).

\section{8}

\section{MDA-5 Recognizes Poly IC}

MDA-5 is structurally related to RIG-I, as it also contains two CARD domains and a helicase domain. MDA-5 was originally identified as a type I IFN-inducible molecule mediating cell cycle arrest and apoptosis in melanoma cells (hence the name melanoma differentiation antigen 5) (Kang et al. 2002, 2004; Kovacsovics et al. 2002). A first indication of a role for MDA-5 in virus recognition came from the observation that a paramyxoviral protein that mediated immune evasion bound to MDA-5 (Andrejeva et al. 2004). In overexpression experiments, MDA-5 was shown to bind poly I:C, and enhanced the interferon response to poly I:C as well as several viruses. Conversely, siRNA mediated knock-down blocked type I IFN induction in response to these stimuli (Yoneyama et al. 2005). MDA-5 was then shown to play an essential role in the detection of Picornaviruses such as encephalomyocarditis virus (EMCV) or Theiler's virus (Gitlin et al. 2006; Kato et al. 2006). In addition, mice deficient in MDA-5 were found to be highly susceptible to EMCV. Although the nature of the natural RNA ligand that engages MDA-5 has so far remained obscure, a surprising observation was that cells derived from MDA-5-deficient mice, as well as $\mathrm{MDA}-5^{-/}$mice stimulated in vivo were found unable to mount a type I IFN response to poly I:C, establishing MDA-5, rather than the several other receptors that bind, or have been shown to be activated by poly I:C, as the dominant receptor mediating the interferon response to poly I:C (Gitlin et al. 2006; Kato et al. 2006). However, the natural viral ligand for MDA-5 has not yet been identified.

In addition to RIG-I and MDA-5, another cytosolic receptor may exist for detecting DNA. Until recently TLR9 was the only innate sensor for detecting microbial DNA. Recent studies indicate that DNA is detected in the cytosol independently of TLR9 (Okabe et al. 2005; Stetson and Medzhitov 2006), but the receptor has not been identified yet. The cytosolic receptor mediating recognition of B-form DNA, unlike RIG-I and MDA-5, signals independently of IPS-1. 


\section{9}

\section{Cell-Type-Dependent Sensing of Viral RNA}

As discussed in the previous sections, immune and nonimmune cell types express characteristic patterns of nucleic acid receptors (Table 1). For example, Melchjorsen and colleagues reported that activation of innate defense against a paramyxovirus is mediated by RIG-I, TLR7, and TLR8 in a cell-type-specific manner (Melchjorsen et al. 2005). They found that nonimmune cells relied entirely on RNA recognition through RIG-I for activation of an antiviral response. In contrast, immune cells such as myeloid cells utilized TLR7 and TLR8. Unlike

Table 1 Nucleic acid receptors

\begin{tabular}{|c|c|c|c|c|}
\hline Receptor & Nucleic acid & Ligands & $\begin{array}{l}\text { Role in IFN- } \alpha / \beta \\
\text { response }\end{array}$ & $\begin{array}{l}\text { Inhibitory } \\
\text { modification }\end{array}$ \\
\hline \multicolumn{5}{|c|}{ Endosomal Toll-like receptors } \\
\hline TLR3 & dsRNA & Poly I:C & $(+)^{\mathrm{a}}$ & \\
\hline TLR7 & ssRNA/siRNA & $\begin{array}{l}\text { Poly U, G, } \\
\text { U-rich, motifs }\end{array}$ & +++ (PDC only) & $2^{\prime}-\mathrm{O}-$ methylation $^{\mathrm{c}}$ \\
\hline TLR8 & ssRNA/siRNA & G, U-rich & - & $2^{\prime}-\mathrm{O}-$ methylation \\
\hline TLR9 & (ss)/dsDNA & CpG motifs ${ }^{\mathrm{b}}$ & $+++(\mathrm{PDC}$ only $)$ & ${ }^{\mathrm{m}} \mathrm{CG}$ Methylation \\
\hline \multicolumn{5}{|c|}{ Cytosolic receptors } \\
\hline PKR & dsRNA & $\begin{array}{l}\text { Poly I:C, >30 } \\
\text { bp, stem loop }\end{array}$ & $(+)^{\mathrm{a}}$ & \\
\hline RIG-I & ss/dsRNA & $\begin{array}{l}5^{\prime} \text { triphosphate } \\
\text { ends }\end{array}$ & +++ & $\begin{array}{l}5^{\prime} \mathrm{m}^{7} \text { guanosine cap } \\
2^{\prime}-\mathrm{O}-\text { methylation } \\
\text { Pseudouridinylation }\end{array}$ \\
\hline MDA-5 & dsRNA & Poly I:C & +++ & \\
\hline (dsDNA-R) & dsDNA & $\begin{array}{l}\text { B-form DNA, } \\
\text { poly dAdT: } \\
\text { dTdA }\end{array}$ & +++ & \\
\hline
\end{tabular}

aBoth TLR3 and PKR have been reported to induce type I IFN production in response to poly I:C. However, compared to MDA-5, their contribution to the type I IFN response in vivo is rather weak ${ }^{\mathrm{b}} \mathrm{CpG}$-containing oligonucleotides (ODN) that induce a strong type I IFN response include CpG-A and CpG-C ODN

${ }^{\mathrm{c}}$ Modifications that have been shown to prevent detection by the receptors indicated and that are frequently found in mammalian nucleic acids 
in nonimmune cells, RNA sensing in paramyxovirus-infected myeloid cells was independent of RIG-I, TLR3, and PKR. Kato and colleagues also found celltype specific involvement of RIG-I in antiviral immune response. In their study type I IFN induction in both fibroblasts and myeloid dendritic cells was RIGI-dependent, while type I IFN induction in PDC was RIG-I-independent (Kato et al. 2005). It is important to note that the mechanisms used for RNA sensing may not only be cell-type-dependent but may also depend on the type of virus and its strategy to enter the target cell and to evade immune recognition. In contrast, recognition of synthetic RNA or of RNA transcribed from vector systems is more predictable because there is no immune evasion and because the mode of delivery is known. Of note, the use of cationic lipids and polycationes leads to both endosomal and cytosolic delivery (Almofti et al. 2003; Boussif et al. 1995) and thus both TLR- and RIG-I-mediated RNA sensing is triggered, provided these receptors are expressed in the cell type examined, and the appropriate RNA ligand is delivered. Of note, subcellular localization of TLR3 is cell-type-specific (Matsumoto et al. 2003): in fibroblasts, TLR3 is located on the cell surface, and the TLR3-mediated activity can be blocked by anti-TLR3 antibodies. In myeloid dendritic cells, TLR3 is found in the cytosolic compartment. A more detailed analysis in TLR3-transfected B cells revealed that TLR3 is detectable in multivesicular bodies, a subcellular compartment situated in the endocytic trafficking pathway (Matsumoto et al. 2003).

\section{0 \\ Conclusion and Future Directions}

Bacteria, fungi, or cellular parasites are recognized via conserved molecules typical for the respective type of pathogen. In contrast, all virus components are formed within the infected host cell; consequently, a virus-specific detection system is more difficult to achieve. It is now evident that host cells are equipped to detect viral nucleic acids. For viral infection in vivo, the following picture is evolving: large parts of the early type I IFN response upon viral infection are due to TLR7 and TLR9 expressed in PDCs; in fact, PDCs are the only considerable source of TLR7- and TLR9-induced type I IFN production upon viral infection. The major advantages of this PDC response are that the presence of viral particles is sufficient for recognition, that viral infection of cells is not required for detection, and that viruses are recognized before viral proteins have a chance to mediate immune evasion. This first wave of type I IFN production plays an important role in limiting viral spread by PDC-derived direct antiviral mechanisms early on, and by sensitizing yet uninfected cells for cytosolic recognition of viral nucleic acid via strong upregulation of the two 
cytosolic helicases, RIG-I and MDA-5. These two cytosolic receptors are then responsible for the second and prolonged wave of type I IFN production and for the induction of apoptosis of virally infected cells. For all four receptors, distinction of self from viral nucleic acid is based on a combination of localization and molecular structure. In this sophisticated system of virus detection, the following situations signal viral danger:

1. Appearance of unmodified RNA in the endosomal compartment of PDCs

2. Appearance of DNA containing unmethylated $\mathrm{CpG}$ motifs in the endosomal compartment of PDCs

3. Unmodified RNA with a triphosphate group at the $5^{\prime}$ end (3pRNA) in the cytosol of any cell type

4. DNA in the cytosol of any cell type

It is still unclear whether long dsRNA in the cytosol is sufficient to elicit an antiviral response via one of the receptors known to date. Although poly I:C is a ligand for MDA-5, long double-stranded RNA seems insufficient as a ligand, and the natural ligand still needs to be identified. In addition to RNAdetecting receptors, the cytosolic receptor for DNA may add new perspectives in therapeutic viral mimicry. With regard to viruses that perform inside the nucleus such as HBV and HIV, uncovering molecular mechanisms of sensing viral nucleic acids in the nucleus appears on the radar of scientific challenges.

\section{References}

Alexopoulou L, Holt AC, Medzhitov R, Flavell RA (2001) Recognition of double-stranded RNA and activation of NF-kappaB by Toll-like receptor 3. Nature 413:732-738

Almofti MR, Harashima H, Shinohara Y, Almofti A, Baba Y, Kiwada H (2003) Cationic liposome-mediated gene delivery: biophysical study and mechanism of internalization. Arch Biochem Biophys 410:246-253

Andrejeva J, Childs KS, Young DF, Carlos TS, Stock N, Goodbourn S, Randall RE (2004) The $\mathrm{V}$ proteins of paramyxoviruses bind the IFN-inducible RNA helicase, mda-5, and inhibit its activation of the IFN-beta promoter. Proc Natl Acad Sci U S A 101:17264-17269

Baltimore D, Becker Y, Darnell JE (1964) Virus-specific double-stranded RNA in poliovirus-infected cells. Science 143:1034-1036

Barchet W, Krug A, Cella M, Newby C, Fischer JA, Dzionek A, Pekosz A, Colonna M (2005) Dendritic cells respond to influenza virus through TLR7- and PKRindependent pathways. Eur J Immunol 35:236-242

Boussif O, Lezoualc'h F, Zanta MA, Mergny MD, Scherman D, Demeneix B, Behr JP (1995) A versatile vector for gene and oligonucleotide transfer into cells in culture and in vivo: polyethylenimine. Proc Natl Acad Sci USA 92:7297-7301 
Bridge AJ, Pebernard S, Ducraux A, Nicoulaz AL, Iggo R (2003) Induction of an interferon response by RNAi vectors in mammalian cells. Nat Genet 34:263-264

Brummelkamp TR, Bernards R, Agami R (2002) A system for stable expression of short interfering RNAs in mammalian cells. Science 296:550-553

Cervantes-Barragan L, Zust R, Weber F, Spiegel M, Lang KS, Akira S, Thiel V, Ludewig B (2006) Control of coronavirus infection through plasmacytoid dendritic-cell-derived type I interferon. Blood 109:1131-1137

Chu WM, Ostertag D, Li ZW, Chang L, Chen Y, Hu Y, Williams B, Perrault J, Karin M (1999) JNK2 and IKKbeta are required for activating the innate response to viral infection. Immunity 11:721-731

Colonna M, Trinchieri G, Liu YJ (2004) Plasmacytoid dendritic cells in immunity. Nat Immunol 5:1219-1226

Colonno RJ, Banerjee AK (1978) Complete nucleotide sequence of the leader RNA synthesized in vitro by vesicular stomatitis virus. Cell 15:93-101

Decatur WA, Fournier MJ (2003) RNA-guided nucleotide modification of ribosomal and other RNAs. J Biol Chem 278:695-698

Diebold SS, Kaisho T, Hemmi H, Akira S, Reis e Sousa C (2004) Innate antiviral responses by means of TLR7-mediated recognition of single-stranded RNA. Science 303:1529-1531

Diebold SS, Montoya M, Unger H, Alexopoulou L, Roy P, Haswell LE, Al-Shamkhani A, Flavell R, Borrow P, Reis e Sousa C (2003) Viral infection switches non-plasmacytoid dendritic cells into high interferon producers. Nature 424:324-328

Doyle S, Vaidya S, O'Connell R, Dadgostar H, Dempsey P, Wu T, Rao G, Sun R, Haberland M, Modlin R, Cheng G (2002) IRF3 mediates a TLR3/TLR4-specific antiviral gene program. Immunity 17:251-263

Elbashir SM, Harborth J, Lendeckel W, Yalcin A, Weber K, Tuschl T (2001) Duplexes of 21-nucleotide RNAs mediate RNA interference in cultured mammalian cells. Nature 411:494-498

Erlandsson L, Blumenthal R, Eloranta ML, Engel H, Alm G, Weiss S, Leanderson T (1998) Interferon-beta is required for interferon-alpha production in mouse fibroblasts. Curr Biol 8:223-226

Farrell PJ, Sen GC, Dubois MF, Ratner L, Slattery E, Lengyel P (1978) Interferon action: two distinct pathways for inhibition of protein synthesis by double-stranded RNA. Proc Natl Acad Sci U S A 75:5893-5897

Field AK, Tytell AA, Lampson GP, Hilleman MR (1967) Inducers of interferon and host resistance. II. Multistranded synthetic polynucleotide complexes. Proc Natl Acad Sci U S A 58:1004-1010

Fitzgerald KA, Rowe DC, Barnes BJ, Caffrey DR, Visintin A, Latz E, Monks B, Pitha PM, Golenbock DT (2003) LPS-TLR4 signaling to IRF-3/7 and NF-kappaB involves the toll adapters TRAM and TRIF. J Exp Med 198:1043-1055

Fromont-Racine M, Senger B, Saveanu C, Fasiolo F (2003) Ribosome assembly in eukaryotes. Gene 313:17-42

Furuichi Y, Shatkin AJ (2000) Viral and cellular mRNA capping: past and prospects. Adv Virus Res 55:135-184 
Gitlin L, Barchet W, Gilfillan S, Cella M, Beutler B, Flavell RA, Diamond MS, Colonna M (2006) Essential role of mda-5 in type I IFN responses to polyriboinosinic:polyribocytidylic acid and encephalomyocarditis picornavirus. Proc Natl Acad Sci U S A 103:8459-8464

Gresser I, Tovey MG, Bandu ME, Maury C, Brouty-Boye D (1976) Role of interferon in the pathogenesis of virus diseases in mice as demonstrated by the use of antiinterferon serum. I. Rapid evolution of encephalomyocarditis virus infection. J Exp Med 144:1305-1315

Hacker H, Redecke V, Blagoev B, Kratchmarova I, Hsu LC, Wang GG, Kamps MP, Raz E, Wagner H, Hacker G, Mann M, Karin M (2005) Specificity in Toll-like receptor signalling through distinct effector functions of TRAF3 and TRAF6. Nature 439:204-207

Harborth J, Elbashir SM, Vandenburgh K, Manninga H, Scaringe SA, Weber K, Tuschl T (2003) Sequence, chemical, and structural variation of small interfering RNAs and short hairpin RNAs and the effect on mammalian gene silencing. Antisense Nucleic Acid Drug Dev 13:83-105

Hartmann G, Battiany J, Poeck H, Wagner M, Kerkmann M, Lubenow N, Rothenfusser S, Endres S (2003) Rational design of new CpG oligonucleotides that combine B cell activation with high IFN-alpha induction in plasmacytoid dendritic cells. Eur J Immunol 33:1633-1641

Hartmann G, Krieg AM (2000) Mechanism and function of a newly identified CpG DNA motif in human primary B cells. J Immunol 164:944-953

Heil F, Hemmi H, Hochrein H, Ampenberger F, Kirschning C, Akira S, Lipford G, Wagner H, Bauer S (2004) Species-specific recognition of single-stranded RNA via tolllike receptor 7 and 8. Science 303:1526-1529

Hemmi H, Kaisho T, Takeuchi O, Sato S, Sanjo H, Hoshino K, Horiuchi T, Tomizawa H, Takeda K, Akira S (2002) Small anti-viral compounds activate immune cells via the TLR7 MyD88-dependent signaling pathway. Nat Immunol 3:196-200

Hemmi H, Takeuchi O, Kawai T, Kaisho T, Sato S, Sanjo H, Matsumoto M, Hoshino K, Wagner H, Takeda K, Akira S (2000) A Toll-like receptor recognizes bacterial DNA. Nature 408:740-745

Honda A, Mizumoto K, Ishihama A (1998) Identification of the $5^{\prime}$ terminal structure of influenza virus genome RNA by a newly developed enzymatic method. Virus Res 55:199-206

Honda K, Yanai H, Mizutani T, Negishi H, Shimada N, Suzuki N, Ohba Y, Takaoka A, Yeh WC, Taniguchi T (2004) Role of a transductional-transcriptional processor complex involving MyD88 and IRF-7 in Toll-like receptor signaling. Proc Natl Acad Sci USA 101:15416-15421

Hornung V, Ellegast J, Kim S, Brzozka K, Jung A, Kato H, Poeck H, Akira S, Conzelmann KK, Schlee M, Endres S, Hartmann G (2006) 5'-Triphosphate RNA is the ligand for RIG-I. Science 314:994-997

Hornung V, Guenthner-Biller M, Bourquin C, Ablasser A, Schlee M, Uematsu S, Noronha A, Manoharan M, Akira S, de Fougerolles A, Endres S, Hartmann G (2005) Sequence-specific potent induction of IFN-alpha by short interfering RNA in plasmacytoid dendritic cells through TLR7. Nat Med 11:263-270 
Hornung V, Rothenfusser S, Britsch S, Krug A, Jahrsdorfer B, Giese T, Endres S, Hartmann G (2002) Quantitative expression of toll-like receptor 1-10 mRNA in cellular subsets of human peripheral blood mononuclear cells and sensitivity to CpG oligodeoxynucleotides. J Immunol 168:4531-4537

Hoshino K, Takeuchi O, Kawai T, Sanjo H, Ogawa T, Takeda Y, Takeda K, Akira S (1999) Cutting edge: Toll-like receptor 4 (TLR4)-deficient mice are hyporesponsive to lipopolysaccharide: evidence for TLR4 as the Lps gene product. J Immunol 162:3749-3752

Hovanessian AG, Brown RE, Kerr IM (1977) Synthesis of low molecular weight inhibitor of protein synthesis with enzyme from interferon-treated cells. Nature 268:537-540

Iordanov MS, Wong J, Bell JC, Magun BE (2001) Activation of NF-kappaB by doublestranded RNA (dsRNA) in the absence of protein kinase R and RNase L demonstrates the existence of two separate dsRNA-triggered antiviral programs. Mol Cell Biol 21:61-72

Isaacs A, Cox RA, Rotem Z (1963) Foreign nucleic acids as the stimulus to make interferon. Lancet 2:113-116

Isaacs A, Lindenmann J (1957) Virus interference. I. The interferon. Proc R Soc Lond B Biol Sci 147:258-267

Janeway CA Jr (1989) Approaching the asymptote? Evolution and revolution in immunology. Cold Spring Harb Symp Quant Biol 54:1-13

Judge AD, Sood V, Shaw JR, Fang D, McClintock K, MacLachlan I (2005) Sequencedependent stimulation of the mammalian innate immune response by synthetic siRNA. Nat Biotechnol 23:457-462

Jurk M, Heil F, Vollmer J, Schetter C, Krieg AM, Wagner H, Lipford G, Bauer S (2002) Human TLR7 or TLR8 independently confer responsiveness to the antiviral compound R-848. Nat Immunol 3:499

Kang DC, Gopalkrishnan RV, Lin L, Randolph A, Valerie K, Pestka S, Fisher PB (2004) Expression analysis and genomic characterization of human melanoma differentiation associated gene-5, mda-5: a novel type I interferon-responsive apoptosisinducing gene. Oncogene 23:1789-1800

Kang DC, Gopalkrishnan RV, Wu Q, Jankowsky E, Pyle AM, Fisher PB (2002) mda-5: An interferon-inducible putative RNA helicase with double-stranded RNA-dependent ATPase activity and melanoma growth-suppressive properties. Proc Natl Acad Sci U S A 99:637-642

Kao CC, Singh P, Ecker DJ (2001) De novo initiation of viral RNA-dependent RNA synthesis. Virology 287:251-260

Kariko K, Bhuyan P, Capodici J, Weissman D (2004a) Small interfering RNAs mediate sequence-independent gene suppression and induce immune activation by signaling through toll-like receptor 3. J Immunol 172:6545-6549

Kariko K, Buckstein M, Ni H, Weissman D (2005) Immunity 23:165-175

Kariko K, Ni H, Capodici J, Lamphier M, Weissman D (2004b) Suppression of RNA recognition by Toll-like receptors: the impact of nucleoside modification and the evolutionary origin of RNA. J Biol Chem 279:12542-12550 
Kato H, Sato S, Yoneyama M, Yamamoto M, Uematsu S, Matsui K, Tsujimura T, Takeda K, Fujita T, Takeuchi O, Akira S (2005) Cell type-specific involvement of RIG-I in antiviral response. Immunity 23:19-28

Kato H, Takeuchi O, Sato S, Yoneyama M, Yamamoto M, Matsui K, Uematsu S, Jung A, Kawai T, Ishii KJ, Yamaguchi O, Otsu K, Tsujimura T, Koh CS, Reis e Sousa C, Matsuura Y, Fujita T, Akira S (2006) Differential roles of MDA5 and RIG-I helicases in the recognition of RNA viruses. Nature 441:101-105

Kawai T, Sato S, Ishii KJ, Coban C, Hemmi H, Yamamoto M, Terai K, Matsuda M, Inoue J, Uematsu S, Takeuchi O, Akira S (2004) Interferon-alpha induction through Tolllike receptors involves a direct interaction of IRF7 with MyD88 and TRAF6. Nat Immunol 5:1061-1068

Kawai T, Takahashi K, Sato S, Coban C, Kumar H, Kato H, Ishii KJ, Takeuchi O, Akira S (2005) IPS-1, an adaptor triggering RIG-I- and Mda5-mediated type I interferon induction. Nat Immunol 6:981-988

Kim DH, Longo M, Han Y, Lundberg P, Cantin E, Rossi JJ (2004) Interferon induction by siRNAs and ssRNAs synthesized by phage polymerase. Nat Biotechnol 22:321-325

Kovacsovics M, Martinon F, Micheau O, Bodmer JL, Hofmann K, Tschopp J (2002) Overexpression of Helicard, a CARD-containing helicase cleaved during apoptosis, accelerates DNA degradation. Curr Biol 12:838-843

Krug A, French AR, Barchet W, Fischer JA, Dzionek A, Pingel JT, Orihuela MM, Akira S, Yokoyama WM, Colonna M (2004a) TLR9-dependent recognition of MCMV by IPC and DC generates coordinated cytokine responses that activate antiviral NK cell function. Immunity 21:107-119

Krug A, Luker GD, Barchet W, Leib DA, Akira S, Colonna M (2004b) Herpes simplex virus type 1 activates murine natural interferon-producing cells through toll-like receptor 9. Blood 103:1433-1437

Krug A, Rothenfusser S, Hornung V, Jahrsdorfer B, Blackwell S, Ballas ZK, Endres S, Krieg AM, Hartmann G (2001a) Identification of CpG oligonucleotide sequences with high induction of IFN-alpha/beta in plasmacytoid dendritic cells. Eur J Immunol 31:2154-2163

Krug A, Towarowski A, Britsch S, Rothenfusser S, Hornung Vv, Bals R, Giese T, Engelmann H, Endres S, Krieg AM, Hartmann G (2001b) Toll-like receptor expression reveals CpG DNA as a unique microbial stimulus for plasmacytoid dendritic cells which synergizes with CD40 ligand to induce high amounts of IL-12. Eur J Immunol 31:3026-3037

Kumar A, Haque J, Lacoste J, Hiscott J, Williams BR (1994) Double-stranded RNAdependent protein kinase activates transcription factor NF-kappa B by phosphorylating I kappa B. Proc Natl Acad Sci U S A 91:6288-6292

Lee YF, Nomoto A, Detjen BM, Wimmer E (1977) A protein covalently linked to poliovirus genome RNA. Proc Natl Acad Sci U S A 74:59-63

Lemaitre B, Nicolas E, Michaut L, Reichhart JM, Hoffmann JA (1996) The dorsoventral regulatory gene cassette spatzle/Toll/cactus controls the potent antifungal response in Drosophila adults. Cell 86:973-983

Li MJ, Bauer G, Michienzi A, Yee JK, Lee NS, Kim J, Li S, Castanotto D, Zaia J, Rossi JJ (2003) Inhibition of HIV-1 infection by lentiviral vectors expressing Pol IIIpromoted anti-HIV RNAs. Mol Ther 8:196-206 
Lund J, Sato A, Akira S, Medzhitov R, Iwasaki A (2003) Toll-like receptor 9-mediated recognition of Herpes simplex virus-2 by plasmacytoid dendritic cells. J Exp Med 198:513-520

Lund JM, Alexopoulou L, Sato A, Karow M, Adams NC, Gale NW, Iwasaki A, Flavell RA (2004) Recognition of single-stranded RNA viruses by Toll-like receptor 7. Proc Natl Acad Sci U S A 101:5598-5603

Maggi LB Jr, Heitmeier MR, Scheuner D, Kaufman RJ, Buller RM, Corbett JA (2000) Potential role of PKR in double-stranded RNA-induced macrophage activation. EMBO J 19:3630-3638

Manche L, Green SR, Schmedt C, Mathews MB (1992) Interactions between doublestranded RNA regulators and the protein kinase DAI. Mol Cell Biol 12:5238-5248

Marie I, Durbin JE, Levy DE (1998) Differential viral induction of distinct interferonalpha genes by positive feedback through interferon regulatory factor-7. EMBO J 17:6660-6669

Marques JT, Devosse T, Wang D, Zamanian-Daryoush M, Serbinowski P, Hartmann R, Fujita T, Behlke MA, Williams BR (2006) A structural basis for discriminating between self and nonself double-stranded RNAs in mammalian cells. Nat Biotechnol 24:559-565

Matsumoto M, Funami K, Tanabe M, Oshiumi H, Shingai M, Seto Y, Yamamoto A, Seya T (2003) Subcellular localization of Toll-like receptor 3 in human dendritic cells. J Immunol 171:3154-3162

Medzhitov R, Preston-Hurlburt P, Janeway CA Jr (1997) A human homologue of the Drosophila Toll protein signals activation of adaptive immunity. Nature 388:394-397

Melchjorsen J, Jensen SB, Malmgaard L, Rasmussen SB, Weber F, Bowie AG, Matikainen S, Paludan SR (2005) Activation of innate defense against a paramyxovirus is mediated by RIG-I and TLR7 and TLR8 in a cell-type-specific manner. JVirol 79:12944-12951

Meylan E, Curran J, Hofmann K, Moradpour D, Binder M, Bartenschlager R, Tschopp J (2005) Cardif is an adaptor protein in the RIG-I antiviral pathway and is targeted by hepatitis $C$ virus. Nature 437:1167-1172

Minks MA, West DK, Benvin S, Baglioni C (1979) Structural requirements of doublestranded RNA for the activation of 2',5'-oligo(A) polymerase and protein kinase of interferon-treated HeLa cells. J Biol Chem 254:10180-10183

Montagnier L, Sanders FK (1963) Replicative form of encephalomyocarditis virus ribonucleic acid. Nature 199:664-667

Moynagh PN (2005) TLR signalling and activation of IRFs: revisiting old friends from the NF-kappaB pathway. Trends Immunol 26:469-476

Muller U, Steinhoff U, Reis LF, Hemmi S, Pavlovic J, Zinkernagel RM, Aguet M (1994) Functional role of type I and type II interferons in antiviral defense. Science 264:1918-1921

Nagano Y, Kojima Y (1958) Inhibition of vaccinia infection by a liquid factor in tissues infected by homologous virus. CR Seances Soc Biol Fil 152:1627-1629

Neumann G, Brownlee GG, Fodor E, Kawaoka Y (2004) Orthomyxovirus replication, transcription, and polyadenylation. Curr Top Microbiol Immunol 283:121-143

Oganesyan G, Saha SK, Guo B, He JQ, Shahangian A, Zarnegar B, Perry A, Cheng G (2005) Critical role of TRAF3 in the Toll-like receptor-dependent and -independent antiviral response. Nature 439:208-211 
Okabe Y, Kawane K, Akira S, Taniguchi T, Nagata S (2005) Toll-like receptor-independent gene induction program activated by mammalian DNA escaped from apoptotic DNA degradation. J Exp Med 202:1333-1339

Paddison PJ, Caudy AA, Bernstein E, Hannon GJ, Conklin DS (2002) Short hairpin RNAs (shRNAs) induce sequence-specific silencing in mammalian cells. Genes Dev 16:948-958

Pebernard S, Iggo RD (2004) Determinants of interferon-stimulated gene induction by RNAi vectors. Differentiation 72:103-111

Pichlmair A, Schulz O, Tan CP, Naslund TI, Liljestrom P, Weber F, Reis ESC (2006) RIGI-mediated antiviral responses to single-stranded RNA bearing 5'-phosphates. Science 314:997-1001

Poltorak A, He X, Smirnova I, Liu MY, Van Huffel C, Du X, Birdwell D, Alejos E, Silva M, Galanos C, Freudenberg M, Ricciardi-Castagnoli P, Layton B, Beutler B (1998) Defective LPS signaling in $\mathrm{C} 3 \mathrm{H} / \mathrm{HeJ}$ and $\mathrm{C} 57 \mathrm{BL} / 10 \mathrm{ScCr}$ mice: mutations in Tlr4 gene. Science 282:2085-2088

Rothenfusser S, Goutagny N, DiPerna G, Gong M, Monks BG, Schoenemeyer A, Yamamoto M, Akira S, Fitzgerald KA (2005) The RNA helicase Lgp2 inhibits TLRindependent sensing of viral replication by retinoic acid-inducible gene-I. J Immunol 175:5260-5268

Rothenfusser S, Tuma E, Endres S, Hartmann G (2002) Plasmacytoid dendritic cells: the key to CpG. Hum Immunol 63:1111-1119

Rozenski J, Crain PF, McCloskey JA (1999) The RNA Modification Database: 1999 update. Nucleic Acids Res 27:196-197

Rubinson DA, Dillon CP, Kwiatkowski AV, Sievers C, Yang L, Kopinja J, Rooney DL, Ihrig MM, McManus MT, Gertler FB, Scott ML, Van Parijs L (2003) A lentivirus-based system to functionally silence genes in primary mammalian cells, stem cells and transgenic mice by RNA interference. Nat Genet 33:401-406

Rudd BD, Smit JJ, Flavell RA, Alexopoulou L, Schaller MA, Gruber A, Berlin AA, Lukacs NW (2006) Deletion of TLR3 alters the pulmonary immune environment and mucus production during respiratory syncytial virus infection. J Immunol 176:1937-1942

Sato M, Hata N, Asagiri M, Nakaya T, Taniguchi T, Tanaka N (1998) Positive feedback regulation of type I IFN genes by the IFN-inducible transcription factor IRF-7. FEBS Lett 441:106-110

Scheel B, Teufel R, Probst J, Carralot JP, Geginat J, Radsak M, Jarrossay D, Wagner H, Jung G, Rammensee HG, Hoerr I, Pascolo S (2005) Toll-like receptor-dependent activation of several human blood cell types by protamine-condensed mRNA. Eur J Immunol 35:1557-1566

Schlee M, Hornung V, Hartmann G (2006) siRNA and isRNA: two edges of one sword. Mol Ther 14:463-470

Sen GC, Sarkar SN (2005) Hitching RIG to action. Nat Immunol 6:1074-1076

Seth RB, Sun L, Ea CK, Chen ZJ (2005) Identification and characterization of MAVS, a mitochondrial antiviral signaling protein that activates NF-kappaB and IRF 3. Cell 122:669-682 
Sharma S, tenOever BR, Grandvaux N, Zhou GP, Lin R, Hiscott J (2003) Triggering the interferon antiviral response through an IKK-related pathway. Science 300:11481151

Shatkin AJ, Manley JL (2000) The ends of the affair: capping and polyadenylation. Nat Struct Biol 7:838-842

Sioud M (2005) Induction of inflammatory cytokines and interferon responses by double-stranded and single-stranded siRNAs is sequence-dependent and requires endosomal localization. J Mol Biol 348:1079-1090

Sledz CA, Holko M, de Veer MJ, Silverman RH, Williams BR (2003) Activation of the interferon system by short-interfering RNAs. Nat Cell Biol 5:834-839

Smith EJ, Marie I, Prakash A, Garcia-Sastre A, Levy DE (2001) IRF3 and IRF7 phosphorylation in virus-infected cells does not require double-stranded RNA-dependent protein kinase R or Ikappa B kinase but is blocked by Vaccinia virus E3L protein. J Biol Chem 276:8951-8957

Stetson DB, Medzhitov R (2006) Recognition of cytosolic DNA activates an IRF3dependent innate immune response. Immunity 24:93-103

Sumpter R Jr, Loo YM, Foy E, Li K, Yoneyama M, Fujita T, Lemon SM, Gale M Jr (2005) Regulating intracellular antiviral defense and permissiveness to hepatitis $\mathrm{C}$ virus RNA replication through a cellular RNA helicase, RIG-I. J Virol 79:2689-2699

Tabeta K, Georgel P, Janssen E, Du X, Hoebe K, Crozat K, Mudd S, Shamel L, Sovath S, Goode J, Alexopoulou L, Flavell RA, Beutler B (2004) Toll-like receptors 9 and 3 as essential components of innate immune defense against mouse cytomegalovirus infection. Proc Natl Acad Sci U S A 101:3516-3521

Theofilopoulos AN, Baccala R, Beutler B, Kono DH (2005) Type I interferons (alpha/ beta) in immunity and autoimmunity. Annu Rev Immunol 23:307-336

Tiscornia G, Singer O, Ikawa M, Verma IM (2003) A general method for gene knockdown in mice by using lentiviral vectors expressing small interfering RNA. Proc Natl Acad Sci U S A 100:1844-1848

Whelan SP, Barr JN, Wertz GW (2004) Transcription and replication of nonsegmented negative-strand RNA viruses. Curr Top Microbiol Immunol 283:61-119

Xiao S, Scott F, Fierke CA, Engelke DR (2002) Eukaryotic ribonuclease P: a plurality of ribonucleoprotein enzymes. Annu Rev Biochem 71:165-189

Xu LG, Wang YY, Han KJ, Li LY, Zhai Z, Shu HB (2005) VISA is an adapter protein required for virus-triggered IFN-beta signaling. Mol Cell 19:727-740

Yang YL, Reis LF, Pavlovic J, Aguzzi A, Schafer R, Kumar A, Williams BR, Aguet M, Weissmann C (1995) Deficient signaling in mice devoid of double-stranded RNAdependent protein kinase. EMBO J 14:6095-6106

Yoneyama M, Kikuchi M, Matsumoto K, Imaizumi T, Miyagishi M, Taira K, Foy E, Loo YM, Gale M Jr, Akira S, Yonehara S, Kato A, Fujita T (2005) Shared and unique functions of the DExD/H-box helicases RIG-I, MDA5, and LGP2 in antiviral innate immunity. J Immunol 175:2851-2858

Yoneyama M, Kikuchi M, Natsukawa T, Shinobu N, Imaizumi T, Miyagishi M, Taira K, Akira S, Fujita T (2004) The RNA helicase RIG-I has an essential function in double-stranded RNA-induced innate antiviral responses. Nat Immunol 5:730-737 
Zheng X, Bevilacqua PC (2004) Activation of the protein kinase PKR by short double-stranded RNAs with single-stranded tails. RNA 10:1934-1945

Zhou A, Paranjape J, Brown TL, Nie H, Naik S, Dong B, Chang A, Trapp B, Fairchild R, Colmenares C, Silverman RH (1997) Interferon action and apoptosis are defective in mice devoid of 2',5'-oligoadenylate-dependent RNase L. EMBO J 16:6355-6363

Zilberstein A, Kimchi A, Schmidt A, Revel M (1978) Isolation of two interferon-induced translational inhibitors: a protein kinase and an oligo-isoadenylate synthetase. Proc Natl Acad Sci U S A 75:4734-4738 